\title{
PHYSICAL METHODS IN CHEMISTRY INVESTIGATIONS OF THE CHEMISTRY INSTITUTE OF ASM
}

\author{
Constantin Turta \\ Institute of Chemistry, Academy of Sciences of Moldova, MD-2028 Chisinau, R.Moldova \\ Fax: (+373 22) 739954, E-mail: turtac@yahoo.com
}

\begin{abstract}
The following classes of compounds are presented: terpenes, cyclic nitrogen compounds, dioximates, carboxylates etc., which have been studied with the participation of experts on physical methods of research - IR, UV-Vis, Atomic, Mössbauer spectroscopy, as well as Mass-spectrometry and Nuclear Magnetic Resonance in the IC ASM. Also, a number of significant scientific results obtained in collaboration of chemists and specialists in physical methods are described.
\end{abstract}

Keywords: IR, UV-Vis, Atomic, NMR, Mössbauer spectroscopy, mass-spectrometry

\section{Introduction}

Many different modern physical methods are widely used for an ample characterization of new chemical substances synthesized in Institute of Chemistry of the ASM. Among them there are X-rays, Infrared, UV-Vis, NMR, ESR, Mössbauer spectroscopy, TG, Mass-spectrometry, Magnetochemisry, Spectral analysis etc. All these methods have been provided with necessary equipment and high skilled specialists. Over time the group of X-rays analysis was transferred in IFA ASM maintaining effective scientific collaboration.

\section{Contribution of physical methods in chemistry investigations}

\section{IR, UV-Vis Spectroscopy}

The idea to organize a spectroscopic group appeared as early as 1958 in the inorganic chemistry department of the Academy of Sciences of Moldova SSR, headed by Professor A.V. Ablov. At first, only the method of UV-VIS spectroscopy was used to study the coordinative compounds of cobalt. As a result of these investigations, were discovered several new dioximates of Co (III) with a hydroxyl group $(\mathrm{OH})$ in the intern sphere.

During the period from 1956 to 1958 eight scientific articles were published and one thesis entitled „Absorption of light by coordination compounds of trivalent cobalt" was proved by M.P. Filippov.

Further, the IR spectroscopy method was studied, which gave the opportunity to investigate the properties of coordination compounds in low frequency region. By the year of the establishment of the Institute of Chemistry of AS MSSR (1959) the spectroscopic team collaborated with all institute divisions.

Since the formation of the Centre of Automation and Metrology, the cooperation of the spectroscopic group was expanded to all institutions with an experimental destination. In addition to obtaining UV-Vis and IR spectra (annual $\approx 3000$ spectra), the common scientific studies were conducted on topics of concerned institutes (Institute of Plant Physiology and Biochemistry, Institute of Applied Physics etc.). Shortly after, they published about 25 scientific articles.

A fruitful collaboration with the Winemaking Institute also took place: different methods of spectral analysis of wine, brandies and other wine products had been developed. The results of these investigations were presented in 13 publications, including methods of prevention of microcrystal tones, disorder of albumin and hydrogen sulphide or saponification.

In the Centre of Automation and Metrology the spectroscopic group collaborated with German company Zeiss Jena (GDR) and some Soviet Union institutes. contracts.

During the same period, some methods of investigation of pectin were developed according to household work

As a result, in 1989 the group leader of the spectroscopic team M.P. Filippov proved his Doctor habilitate thesis in chemistry [1]. Publications - 68 articles.

\section{Mass-spectrometry}

Mass-spectrometry (MS) is a widely used method for studying of gaseous substances. This method enables obtaining characteristic information about an investigated object, as it isn't affected by other effects (solvent, crystal lattice, interaction between molecules) during the study.

The development of mass-spectrometry in the Institute of Chemistry of ASM began with the purchase of installations MX-1303 (1968) and MX-1320 (1976). The objects of study were traditional for IC ASM and were dictated by the scientific topics of the Institute laboratories. 
Most of organic substances are considered to be good objects for mass spectrometry studies. MS is particularly important in the investigation of natural substances, because processes of their preparation, separation and identification are very difficult. By studying the mass spectra of diterpenic alcohols of abienols, which are characterized by a high liability and common properties, interesting data have been obtained on their identification and development of methods for their efficient extraction and synthesis. It was found that MS can serve as a quick and adequate analysis of natural substances [2].

Izatine and its derivatives represent another class of organic substances studied with MS. The investigation of deuteride compounds gave the opportunity to suggest behaviour lows of this class of substances under the action of electron impact $[3,4]$.

In the field of inorganic chemistry an ample study of coordination compounds was performed: monooximates, dioximates of $\mathrm{Ni}$ (II), $\mathrm{Cu}$ (II) and Pd (II) [5]; coordination compounds of $3 \mathrm{~d}$ metal with Schiff bases, derivatives of thio- and selenocarbasides [6-12], of various metal (s, p, d, f) carboxylates [9-12]. As a result of these studies, various schemes were suggested for the general fragmentation under the impact of electrons, and were proven that there was a close correlation between the substances in the crystalline and gas states. Transition metal carboxylates (3d) proved to be more labile in the mass spectrometry study and suffer of different regrouping, as a result of which different polynuclear structures were detected. Mass-spectrometry data were used as points of reference to predict routes of synthesis of new substances with nontrivial nuclei $[13,14]$.

Atomic spectroscopy for solving scientific and practical tasks

The laboratory of atomic spectroscopy was founded in 1979. The following analysis methods are carried out in this laboratory: atomic spectroscopy methods (atomic absorption, flame photometry, emission spectral analysis), molecular spectroscopy methods (photo colorimetric method) and chemical methods (volumetric, gravimetric method).

Utilization of the entire set of methods provides the most complete picture of the chemical composition of the analyzed samples. About 50 different parameters can be defined in the laboratory, more than half of which is done by the atomic absorption method. In addition, the emission spectral analysis provides an overview spectrum, where about 40 elements can be simultaneously determined semi-quantitatively, and about 20 items quantitatively.

These laboratory features are widely used by research institutes of the Academy of Sciences to solve various scientific and applied problems.

Among the major problems that were dealt with by the laboratory of atomic spectroscopy together with the Institute of ASM and other scientific organizations, the following tasks should be mentioned:

- regional analysis of ground and surface water;

- changes in micro-and macro-composition of plants, with their feeding and treating of various drugs;

- study of the soil, rocks and sediments composition;

- analysis of the effectiveness of water purification by various methods (electroflotation process, use of diatomite, activated charcoal etc.);

- analysis of various complex compounds;

- optimization of conditions for synthesis of propolis.

Among the applications, addressed to Moldovan economic agents, the following should be noted:

- study of the micro-and macro-components impact on wines and brandies quality, and methods to improve them;

- analysis of drugs quality;

- the influence of chemical composition on glass quality;

- study of underground waters stability;

- analysis of food products quality;

- analysis of the quality of drinking and mineral water;

- study of the slag composition from smelters, metal and alloys, sand, clay, etc. for industrial enterprises in Moldova.

For over 30 years, the laboratory of atomic spectroscopy participated in solving of a broad range of scientific problems for scientific organizations in other countries (SU, Moscow; SU Chernovtsy; Institute of Oceanology, Odessa; Institute of Glass, Romania). In collaboration with leading laboratories from other countries, it successfully participated in the certification of standard samples of soil, carried out by the Institute of Geochemistry in Irkutsk.

The laboratory is accredited by the Standards Department of the Republic of Moldova.

\section{Mössbauer Spectroscopy (SM) method}

Mössbauer spectroscopy operates in the Institute of Chemistry of ASM since 1975. From that date until present time all studies were conducted on isotope Fe-57. The five parameters of the Mossbauer spectroscopy are: the isomer 
shift, quadrupol splitting, magnetic hyperfine interaction, probability of Mössbauer Effect and peaks asymmetry (Fig. 1).
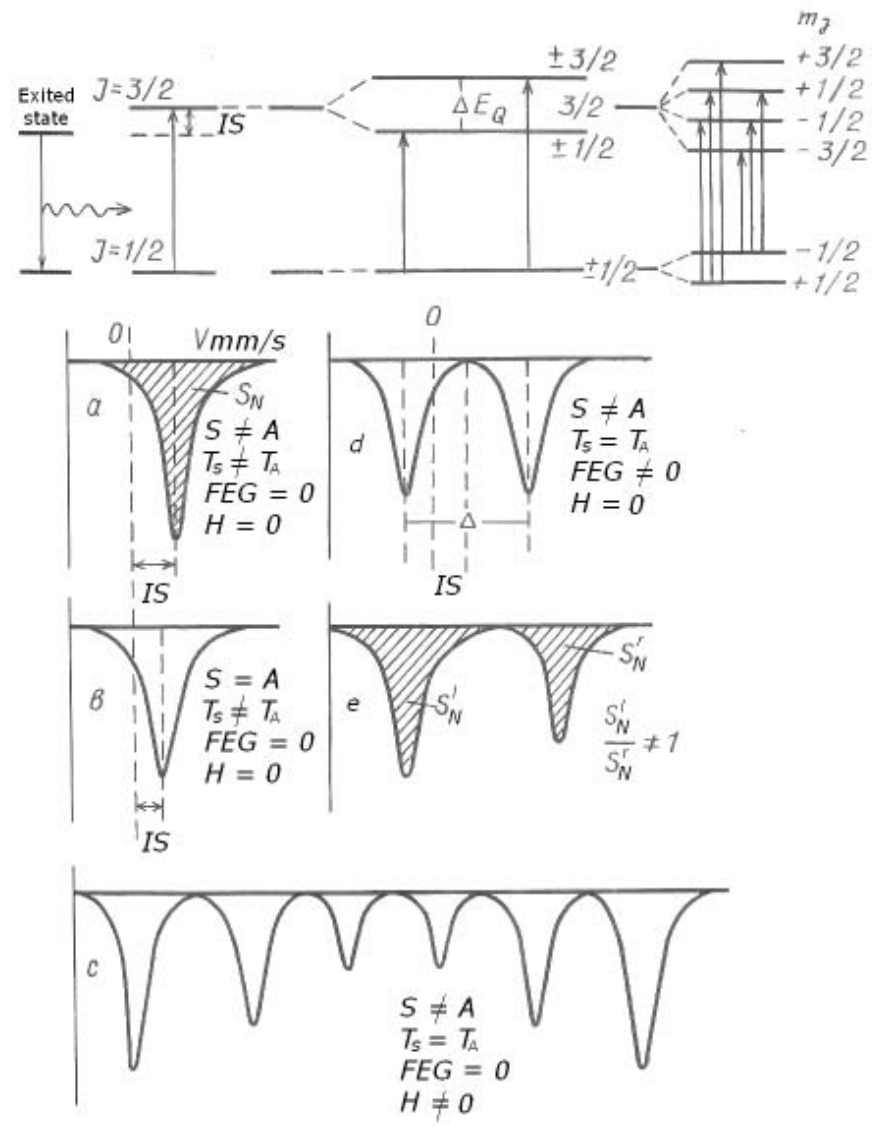

Fig. 1. Mössbauer Spectra Parameters: IS = Isomer shift; $\Delta \mathrm{E}_{\mathrm{o}}$ or $\Delta=$ Quadrupole splitting; Probability of effect, $S_{\mathrm{N}}$; Asymmetry of picks $A=\left(S^{1} \mathbf{n o r m} / \mathbf{S}_{\mathrm{N}}^{\mathrm{r}}\right) \# \mathbf{1}$; Hyperfine magnetic interaction, $\mathrm{H} \# \mathbf{0}$.

The values of obtained parameters provide researchers information about electronic structure of the Mössbauer nucleus environment and dynamic oscillations of an atom in the molecule crystal lattice. Many classes of chemicals, objects of solid body physics, biology samples as well as some archaeological items have been studied by Mossbauer spectroscopy. Different coordination compounds, ion changers, absorbents, oxides, etc. are studied among chemical substances.
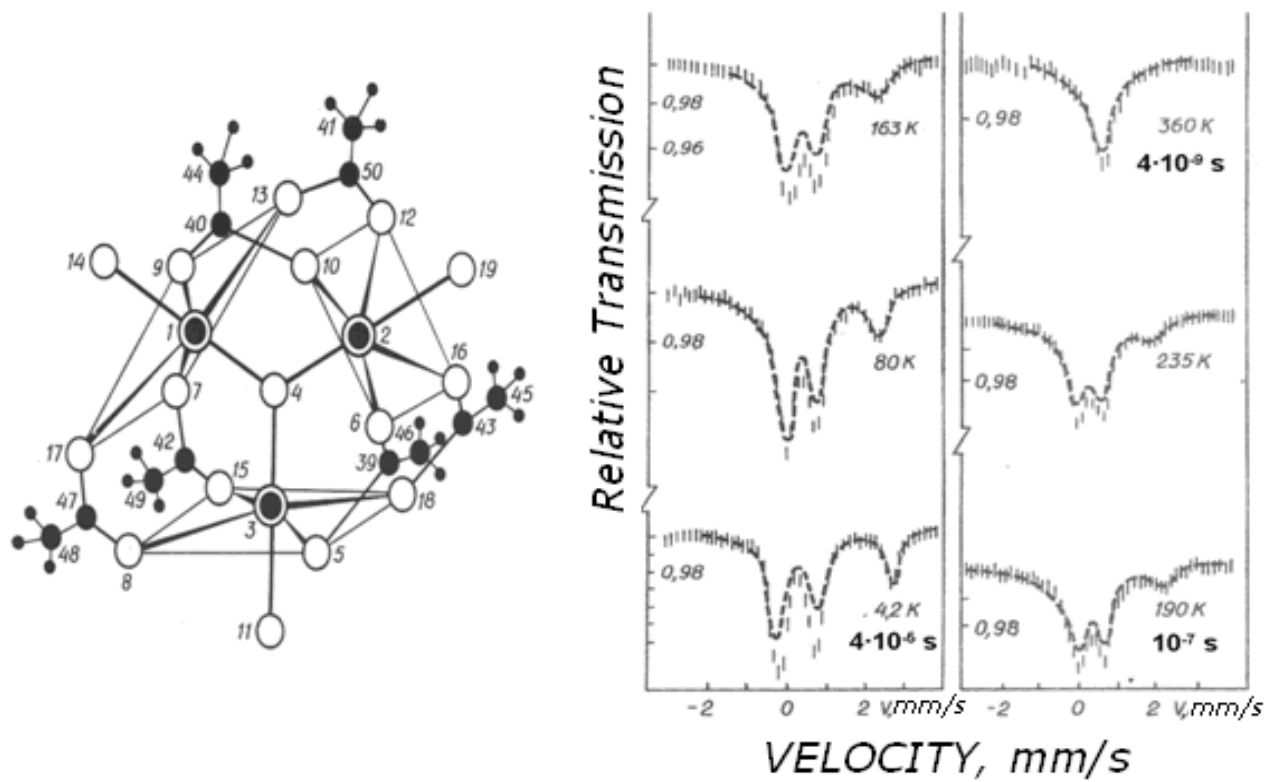

Fig. 2. Molecular structure of the cluster $\left[\mathrm{Fe}_{3} \mathrm{O}\left(\mathrm{O}_{2} \mathrm{CCF}_{3}\right)_{6}\left(\mathrm{H}_{2} \mathrm{O}\right)_{3}\right] .3 .5 \mathrm{H}_{2} \mathrm{O}[16]$ and the Mössbauer spectra of iron acetate with mixed valence at different temperatures [15]. 
Next, several obtained scientific results will be detailed, which are of particular interest and that were the most cited in scientific literature worldwide.

An article was published on Mössbauer spectra of iron acetate of mixed valence in 1973 [15]. The temperature dependence of Mössbauer spectra of the complex $\left[\mathrm{Fe}^{\mathrm{III}}{ }_{2} \mathrm{Fe}^{\mathrm{II}} \mathrm{O}\left(\mathrm{CH}_{3} \mathrm{COO}\right)_{6}\left(\mathrm{H}_{2} \mathrm{O}\right)_{3}\right] \cdot 2 \mathrm{H}_{2} \mathrm{O}$ (Fig.2) shows that at low temperatures $(4.2-80 \mathrm{~K})$ the spectrum has 3 peaks of different intensity, which were sufficient approximated with two doublets with intensities of $2: 1$.

The parameters of Mössbauer spectrum indicates the presence of $\mathrm{Fe}(\mathrm{III})$ ions in a high spin state $\mathrm{S}=5 / 2$ (more intensive doublet) and $\mathrm{Fe}(\mathrm{II})$ ions $\mathrm{S}=2$ (less intensive doublet) corresponding with excellent data analysis of the complex chemical composition. With temperature increasing the spectrum radically changes and at $360 \mathrm{~K}$ spectrum is approximated with a very broad singlet that can be fitted as a doublet with a small quadrupol splitting. This change of Mossbauer spectrum form was interpreted by three groups of researchers $[15,17,18]$. They based on dynamic delocalization model of type electron space-time for a three centres system. According to this model, the spectrum depends on the ratio of an electron presence around a nucleus $\left(\tau_{\mathrm{e}}\right)$ and the characteristic measuring time of the method $\left(\tau_{\mathrm{o}}\right)$. In the case of Mossbauer spectroscopy for isotope Fe-57 $\left(\tau_{\mathrm{o}}=1 \cdot 10^{-7} \mathrm{~s}\right)$.

At $\left(\tau_{\mathrm{e}}>>\tau_{\mathrm{o}}\right)$ all states of Mössbauer nuclei will be presented in Mossbauer spectroscopy, and at $\left(\tau_{\mathrm{e}}<<\tau_{\mathrm{o}}\right)$ it will be a spectrum of an average state (taking into account the stoichiometric data). If $\tau_{\mathrm{e}} \sim \tau_{\mathrm{o}}$ the spectrum shape will be kind of a "trough" with the absorption of gamma rays from the most negative relative velocity to the most positive in the system of the several Mossbauer isotope states. The simulation of experimental spectra with theoretical some led to the following $\tau_{\mathrm{e}}$ values: $2,4 \cdot 10^{-6} \mathrm{~s}$ at $17 \mathrm{~K}$ and $2,5 \cdot 10^{-9} \mathrm{~s}$ at $296 \mathrm{~K}$. Further studies conducted in the inorganic chemistry sector of the IC ASM on iron carboxylates of mixed valence resulted in the following conclusions: the X-rays study demonstrated that iron carboxylates of mixed valence have the $\mu_{3}$-oxo triangular structure; there is an antiferomagnetic interaction between iron ions; electron delocaliyation of the space-time type takes place, and its speed depends on temperature as well as the donor-acceptor nature of ligands from the internal and external cluster sphere that enables the routing of this process. For iron ions in the triangle with a high symmetry and a more equivalent position, a dynamic electron delocalization with a higher speed can be observed. It should be mentioned that „intermolecular” electron transfer occurs "slow” in iron polycluster carboxylates of mixed valence, synthesized by "stitching" of $\mu_{3}$-oxo-iron acetate (III) with $\mu_{3}$-oxo-iron acetate of mixed valence. [19]

Another pioneer achievement in the class of iron carboxylates was the synthesis and study of tetranuclear iron carboxylates - hexaaqua-tetrakis ( $\mu$-trifluoracetato-trifluoroacetato $\left(\mathrm{O}, \mathrm{O}^{\prime}\right)$ ) - $\mu_{3}$ - dioxo - tetrafier(III) trihydrate [19,20]. As a result, it was determined that the structure of this carboxylate had a form of "butterfly" (X-ray method) (Fig.3).

From Mössbauer spectroscopy data it clearly apperas that the electronic structure of Fe(III) ions of high spin is arranged in groups of two with different values of electric field gradient (EFG) around the nucleus. Magnetic properties are characterized by antiferomagnetic interaction between paramagnetic ions of trivalent iron with the following values of the magnetic exchange parameters $\mathrm{J}_{\text {(perimeter) }}=-18 \mathrm{~cm}^{-1}, \mathrm{~J}_{13}=-10 \mathrm{~cm}^{-1}$ and $\mathrm{J}_{24}=-24.7 \mathrm{~cm}^{-1}$. For the first time, an original method was offered to describe the component parts of a Mossbauer spectrum which presents a superposition of component spectra at the temperature dependence of dynamic parameter $\left\langle\mathrm{x}^{2}\right\rangle$ (average squared projection amplitude of nucleus or atom oscillations, from direction of gamma ray spread) estimated from Mossbauer spectra and data of X-ray sample analysis at different temperatures [19].
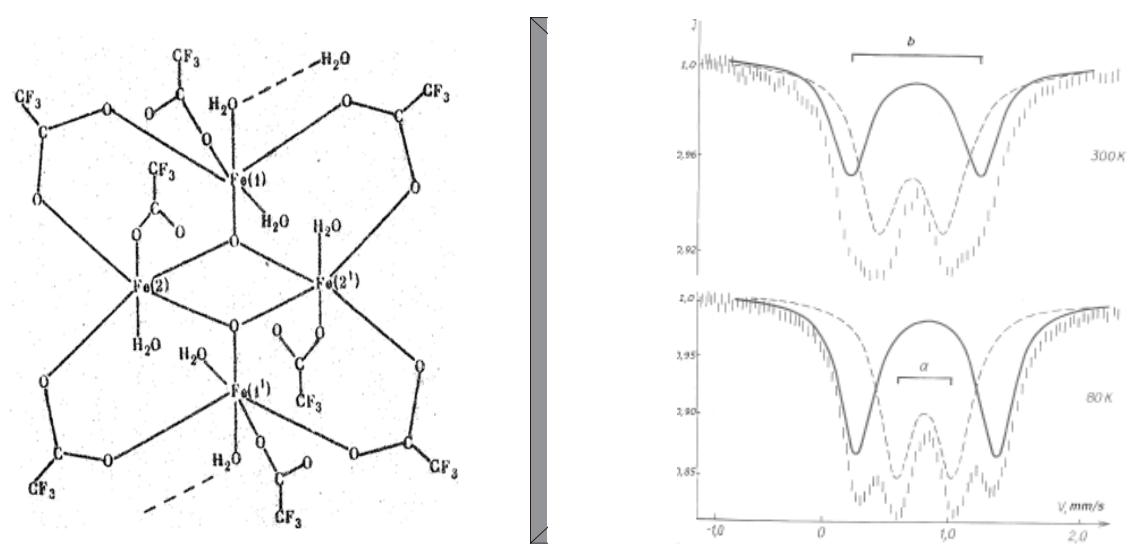

Fig.3. Molecular structure and Mössbauer spectra of tetranuclear iron carboxyl ate $\left[\mathrm{Fe}_{4} \mathrm{O}_{2}\left(\mathrm{O}_{2} \mathrm{CCF}_{3}\right)_{8}\left(\mathrm{H}_{2} \mathrm{O}\right)_{6}\right] \cdot 2 \mathrm{H}_{2} \mathrm{O}[20]$.

In 2003-2004 [21,22] it was synthesised and studied heterotetranuclear $\mu_{3}$-dioxo iron tricloracetate, that contained three iron(III) and one $\mathrm{Eu}(\mathrm{III})$ ions, $\left[\mathrm{Fe}_{3} \mathrm{EuO}_{2}\left(\mathrm{CCl}_{3} \mathrm{COO}\right)_{8} \mathrm{H}_{2} \mathrm{O}(\mathrm{THF})_{3}\right] \cdot \mathrm{THF}$, and had similar structure with other metal carboxylates of "butterfly" type (Fig.4.). The tetranuclear molecule presents a structure of "butterfly" with two Fe ${ }_{2} \mathrm{Eu}$ 
triangles and with a common aspect Eu $\cdots$ Fe. Metals are linked by two $\mu_{3}$-oxo centres and eight carboxylic ligands. Each metal atom is surrounded only by oxygen atoms: six for iron and eight for europium. $\mathrm{Fe}(3)$ coordinates both oxygen- $\mu_{3}$ atoms, while $\mathrm{Fe}(1)$ and $\mathrm{Fe}(2)$ bonds only one - $\mathrm{O}(1)$ and $\mathrm{O}(2)$ respectively. Axial coordination positions of $\mathrm{Fe}(1)$ and $\mathrm{Fe}$ (2) are occupied by oxygen atom of THF. Unlike Fe(2), the atom of Fe(1) coordinates a molecule of water.
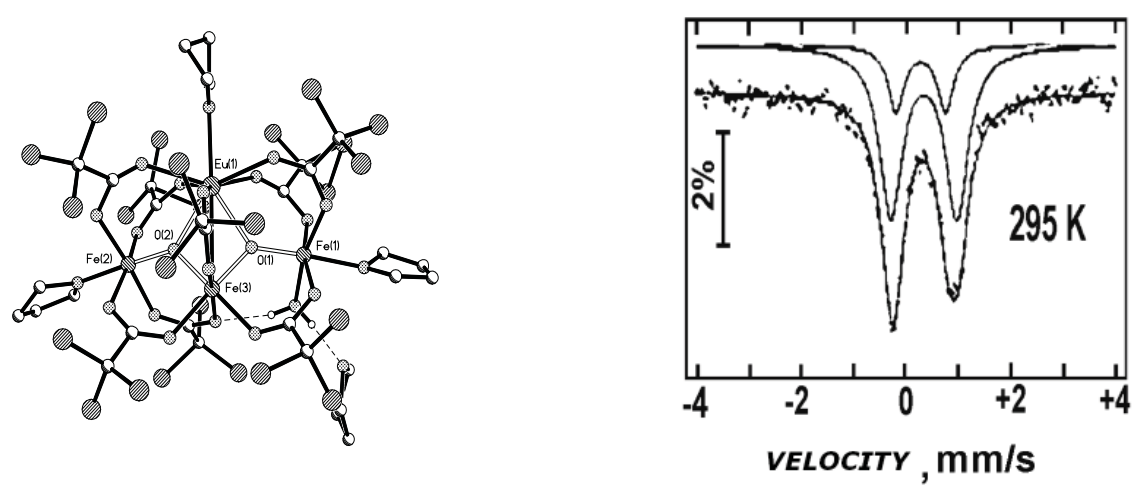

Fig. 4. Molecular structure and Mossbauer spectra of the complex $\left[\mathrm{Fe}_{3} \mathrm{EuO}_{2}\left(\mathrm{CCl}_{3} \mathrm{COO}\right)_{8} \mathrm{H}_{2} \mathrm{O}(\mathrm{THF})_{3}\right]$ associated with two THF solvent molecules [21,22].

All equatorial oxygen atoms come from carboxylic groups, which are coordinated in syn-syn form. Thus, the surrounding of three iron atoms in complex is slightly different. A water molecule forms two hydrogen bonds with the oxygen atoms of a solvated THF and a carboxylic ligand. It is assumed that the last play the role of the second bridgeligand, which is missing between atoms of $\mathrm{Fe}(1)$ and $\mathrm{Fe}(2)$.

Later was obtained and characterized a complete set of compounds of this series, where $\mathrm{Eu}(\mathrm{III})$ ions were substituted with $\mathrm{La}^{\mathrm{III}}, \mathrm{Ce}^{\mathrm{III}}, \mathrm{Pr}^{\mathrm{III}}, \mathrm{Nd}^{\mathrm{III}}, \mathrm{Sm}^{\mathrm{III}}, \mathrm{Gd}^{\mathrm{III}}, \mathrm{Tb}^{\mathrm{III}}, \mathrm{Ho}^{\mathrm{III}}, \mathrm{Er}^{\mathrm{III}}$ and $\mathrm{Yb}^{\mathrm{III}}$ ions. According to the parameters of Mossbauer spectra of these compounds, where $\mathrm{Ln}=\mathrm{Eu}, \mathrm{Ce}, \mathrm{Pr}, \mathrm{Nd}, \mathrm{Sm}$, it was found that electronic states of two Fe(III) configurations (those "butterflies wings", Fe1 and Fe2) are close by symmetry as well as summary density of the electron cloud around the nuclei and also differs from the position of iron "head-tail", Fe3. At temperatures below $15 \mathrm{~K}$, the Mossbauer spectra of such complexes have a form of doublet corresponding to paramagnetic Fe(III) ions ( $\mathrm{S}=5 / 2)$ and a sextet (Zeeman spectrum) indicating the presence of magnetic ordering around the other Fe (III) atoms position.

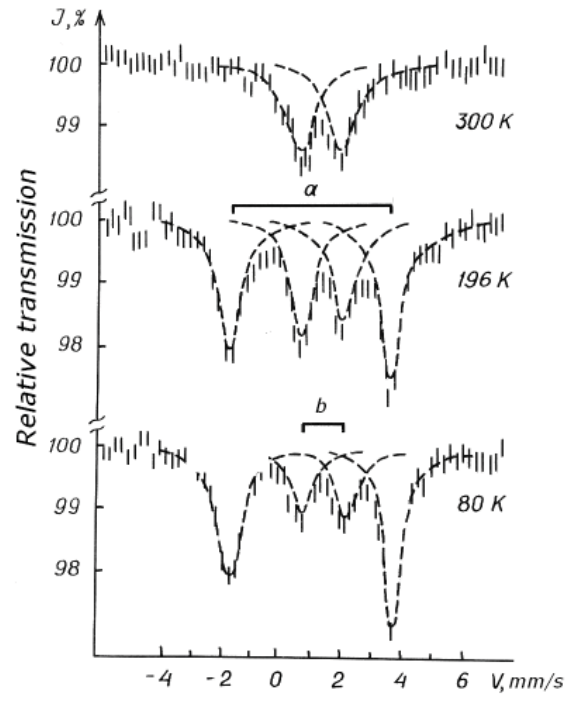

Fig.5. Mössbauer spectra of thiosemicarbazone Cat $\left[\mathrm{Fe}\left(\mathrm{R}\right.\right.$-thasa) $\left.{ }_{2}\right]$.nSolv at different temperatures.

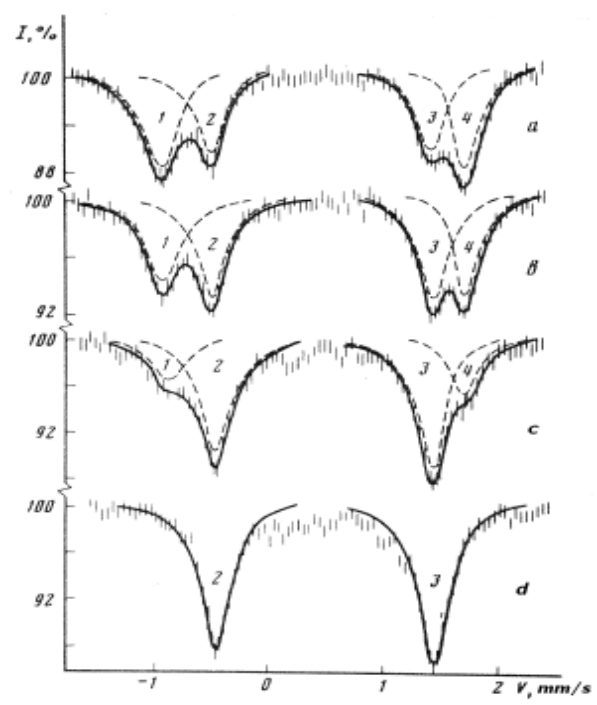

Fig.6. The time and temperature dependence of Mossbauer spectra of $\left[\mathrm{Fe}(\mathrm{DfgH})(\mathrm{Dfg}) \mathrm{Py}_{2}\right] \cdot \mathrm{nSolv}$. a-c At the initial moment of giving off; d - After standing at $300 \mathrm{~K}$ during long time.

Another interesting phenomenon studied extensively in IC ASM with Mossbauer spectroscopy is the effect of spin transition ("cross-over") in iron(III) thiosemicarbasone, with the composition Cat[Fe(R-thasa)2].nSolv, where Cat = cation, $\mathrm{R}=$ different electron-donor or electron-acceptor radicals. In this class of substances ${ }^{6} \mathrm{~A}_{1} \leftrightarrow{ }^{2} \mathrm{~T}_{2}$ transition is achieved. It can be observed (Fig.5) that the Mössbauer spectra change at different temperatures in a rather long set of coordination compounds of this class of substances [23-26]. At low temperatures (about $80 \mathrm{~K}$ ) the spectrum contains one 
or two doublets, but at high temperatures there is only a single doublet. The parameters of Mössbauer spectra correspond to iron(III) ions in low spin state $\left(\mathrm{S}=1 / 2\right.$, with large values of quadrupole splitting $\left.\Delta \mathrm{E}_{\mathrm{Q}}\right)$ and to iron ions in the state of uncoupled spin $\left(\mathrm{S}=5 / 2\right.$, with small values of quadrupole splitting $\left.\Delta \mathrm{E}_{\mathrm{Q}}\right)$.

The topic of dioximates was developed throw synthesis and Mössbauer spectroscopy (MS) investigations of a whole range of compounds with coordinative core $\mathrm{Fe}^{\mathrm{II}} \mathrm{N}_{4} \mathrm{~A}_{2}$, where $\mathrm{A}=\mathrm{N}$, As, $\mathrm{P}, \mathrm{C}$ [23, 27,28]. An intermolecular red-ox process with participation of oxime takes place in solid samples of iron(III) alpha-benzyldioximates with ketones. MS measurements of solid samples at different temperatures and variable time (Fig. 6.) allowed studying the kinetics of an intermolecular red-ox reaction with transfer of electron from ligand to $\mathrm{Fe}(\mathrm{III})$.

The studied reaction kinetics Ligand $\stackrel{\overline{\mathrm{e}}}{\mathrm{F}} \mathrm{Fe}(\mathrm{III}) \rightarrow \mathrm{Fe}(\mathrm{II})$ is characterized by the formal order of this transformation kinetics $\mathrm{n}=0.50, \mathrm{~K}=0.070 \mathrm{~h}^{-1}$, activation energy $\Delta \mathrm{E}^{*} \sim 111 \mathrm{~kJ} / \mathrm{mol}$, and the pre-exponential coefficient $\mathrm{Z}=8.10^{17}$ which is in the limits of other topochimical reaction. Through this study it was demonstrated the possibility of using MS in the investigation of topochemical reactions.

MS was used to study the formation of complexes with active groups of ionic exchange resins. The treatment of different types of such substances (KY-2, КВ-2, АН-31, АВ-17, ЭДЭ-10П, АН-2ФНб АВ-16Г et al.) with salts of iron ions, subjecting them to various other actions (thermal processing, variation of environmental acidity, $\mathrm{pH}$, etc.) and then their studying with Mossbauer spectroscopy gave the opportunity to demonstrate the formation of chemical bounds Fe - Donor from groups of ionic exchange resins, or redox transformations in their composition, as well as dynamics of complex oscillations in their generator phase [29-31].

The scientific results obtained using Mössbauer spectroscopy became a part of 4 doctor habilitat theses in science $[19,28,31,32]$ and more than $15 \mathrm{PhD}$ thesis [22, 23,25-27, 29, 30, 33-38 et al.] thereby contributing to increasing the professional level of researchers.

\section{Nuclear Magnetic Resonance (NMR)}

Method of nuclear magnetic resonance (NMR) began operating in IC ASM in 1975. Main users of this method have been and are specialists in organic chemistry, who use it to control the purity of synthesized substances and to determine their structure.

NMR group has actively participated in caring out of many scientific themes of the laboratories from IC AŞM and from academic Departments. One of the interesting topics was the polymer synthesis inclusive graft polymers for different areas. Especially it should be mentioned the polymers for optoelectronics - field developed in collaboration with physicists of IAF of ASM and centre of optoelectronics of Moldova State University (MSU).

At the Department of Organic Chemistry of MSU, 300 monomers of styrene with active functional groups in benzene ring $\left(\mathrm{NH}_{2}, \mathrm{NCO}, \mathrm{NCS}\right)$ wee studied. All of them have been used to obtain new polymers. The main control methods of reactions of synthesis have been IR, UV-Vis, NMR spectral methods. The obtained scientific results were presented at various scientific forums and published in specialized journals.

IR, UV-Vis and NMR spectra of these compounds (267 monomers) were interpreted and presented in the form of atlases $[39,40]$. In 1985, a monograph of nitrogen-containing vinylarenes was published [41].

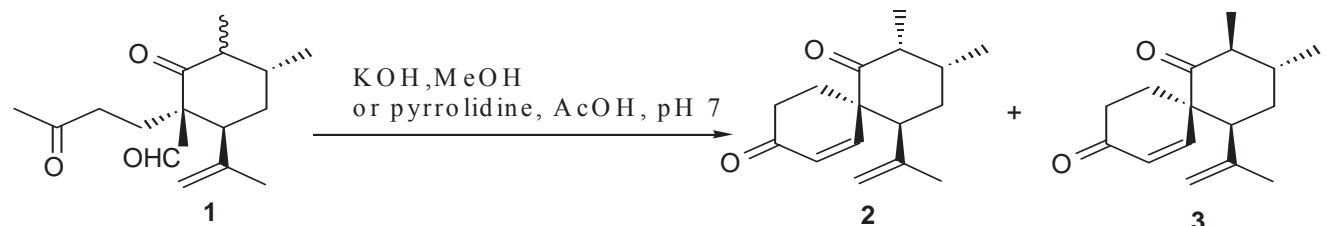

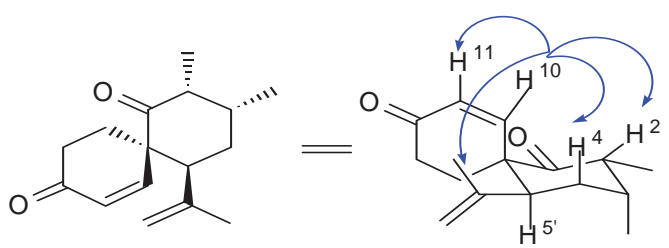

2

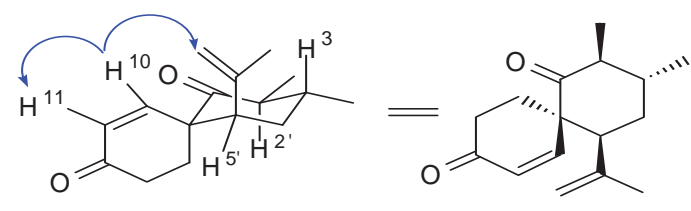

3

Scheme1. The transformation of the decalin moiety in different conditions.

The construction of the decalin moiety in clerodines via Robinson annulation has been studied. As the part of this investigation, the structure of compounds $\mathbf{2 , 3}$ (scheme 1) were elucidated by 2D-NMR, more concretely - by Nuclear Overhauser Effect (NOE) in NMR method. This technique permits elucidating the spin polarization from one nuclear 
spin to another, through space (not through bonds) and it is used to determine the structure of complicated organic molecules. Furthermore, the distance can be derived from the observed NOEs, so that the precise, three-dimensional structure of the molecule can be reconstructed. Lower one example is presented.

A clear NOE difference interaction was observed between $\mathrm{H} 10$ and $\mathrm{H} 2, \mathrm{H} 4$ and the $\mathrm{CH}_{3}$ at the isopropenyl group, which suggests structure 2. The equatorial position of isopropenyl group was further proven by the coupling constants of H5', which were $13.6 \mathrm{~Hz}$ and 3,5 Hz respectively, indicating an axial-axial and axial-equatorial coupling. In compound 3, a clear NOE difference was observed between $\mathrm{H} 10$ and $\mathrm{H} 11$ and the $\mathrm{CH}_{2}$ of the isopropenyl group, but no NOE difference was observed for $\mathrm{H} 2$ and $\mathrm{H} 4$. This indicated an axial position of the isopropenyl group, which was supported by the small coupling constants of $\mathrm{H} 5$ ' [42].

In continuation of decalin direction the construction of natural antifeedants Dehydroclerodanin and Lupulin-C via 1,4 and 1,2-additions reactions has been studied (scheme 2).

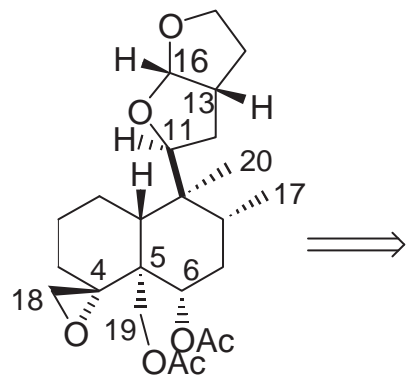

Dehydroclerodin<smiles>C=C1CCC[C@H]2[C@H]([C@@H]3C[C@H]4CCO[C@H]4O3)[C@H](C)C[C@H](OC(C)=O)[C@]12C</smiles>

Lupulin C<smiles>C[C@@H]1CC(=O)C2=CCCC[C@H]2[C@]1(C)[C@H]1C[C@H]2CCO[C@H]2O1</smiles>

1<smiles>C=C(C)[C@@H]1CC(=O)[C@](C)([C@H]2C[C@H]3CCO[C@H]3O2)[C@H](C)C1</smiles>

2

\section{Annulation via a 1,4-addition}

The structure of methyl $18 \alpha \mathrm{H}$-scalar-16 $\alpha$-hydroxy-5(6),17(25)-dien-19-oate (21) (scheme 3) was determine by high resolution mass spectrometry and a detailed 2D-NMR analysis.<smiles>C=CCCCCC1CC(=O)C[C@H](C)[C@]1(C)C1C[C@H]2CCO[C@H]2O[C@H]1CCCC(C)(C)Br</smiles>

Scheme 2. The transformation of dehydroclerodin to cyclized decalin 2.

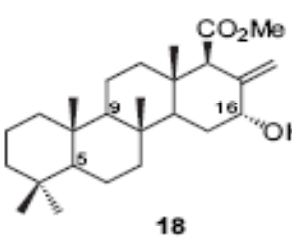

18

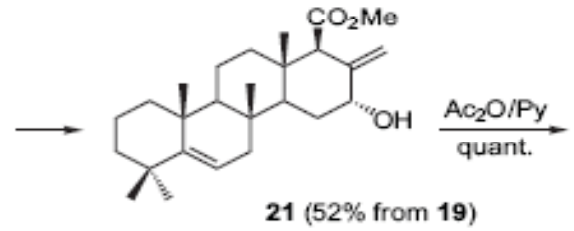
(16\% from 20$)$<smiles>CCCCC1CC(=O)C[C@H](C)[C@]1(C)[C@H]1C[C@H]2CCO[C@H]2O[C@H]1C(=O)O</smiles>

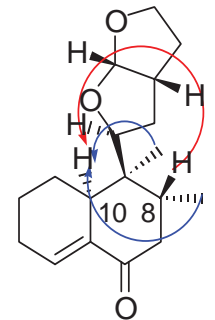

2 
For the construction of ring A, a four carbon fragment had been introduced at C10. The configuration at C10 was determined in the cyclized decalin 2 by NMR, where no NOE between H-10 and H-8 could be detected, whereas a clear NOE was observed between $\mathrm{H}-10$ and both the methyl groups at $\mathrm{C} 8$ and $\mathrm{C} 9$, which is indicative for an $\alpha$-position of this proton [43].

Scalarane sesquiterpenes represent an interesting class of organic substances which was studed with the participation of our institute's specialists in organic chemistry. The functionalization of the B-ring of the scalarane framework has been achieved for the first time by a radical relay halogenation (RRH) synthetic method. Lower some theoretical considerations explaining the course of $\mathrm{RRH}$ reaction are presented.

First of all, the molecular formula $\mathrm{C}_{26} \mathrm{H}_{40} \mathrm{O}_{3}$, deduced by the sodiated ion peak at $\mathrm{m} / \mathrm{z} 423(\mathrm{M}+\mathrm{Na})$ in the HRESIMS spectrum, exhibited the expected additional unsaturation degree with respect to the starting product - Methyl $18 \alpha \mathrm{H}-$ scalar-16 $\alpha$-hydroxy-17(25)-en-19-oate (18).
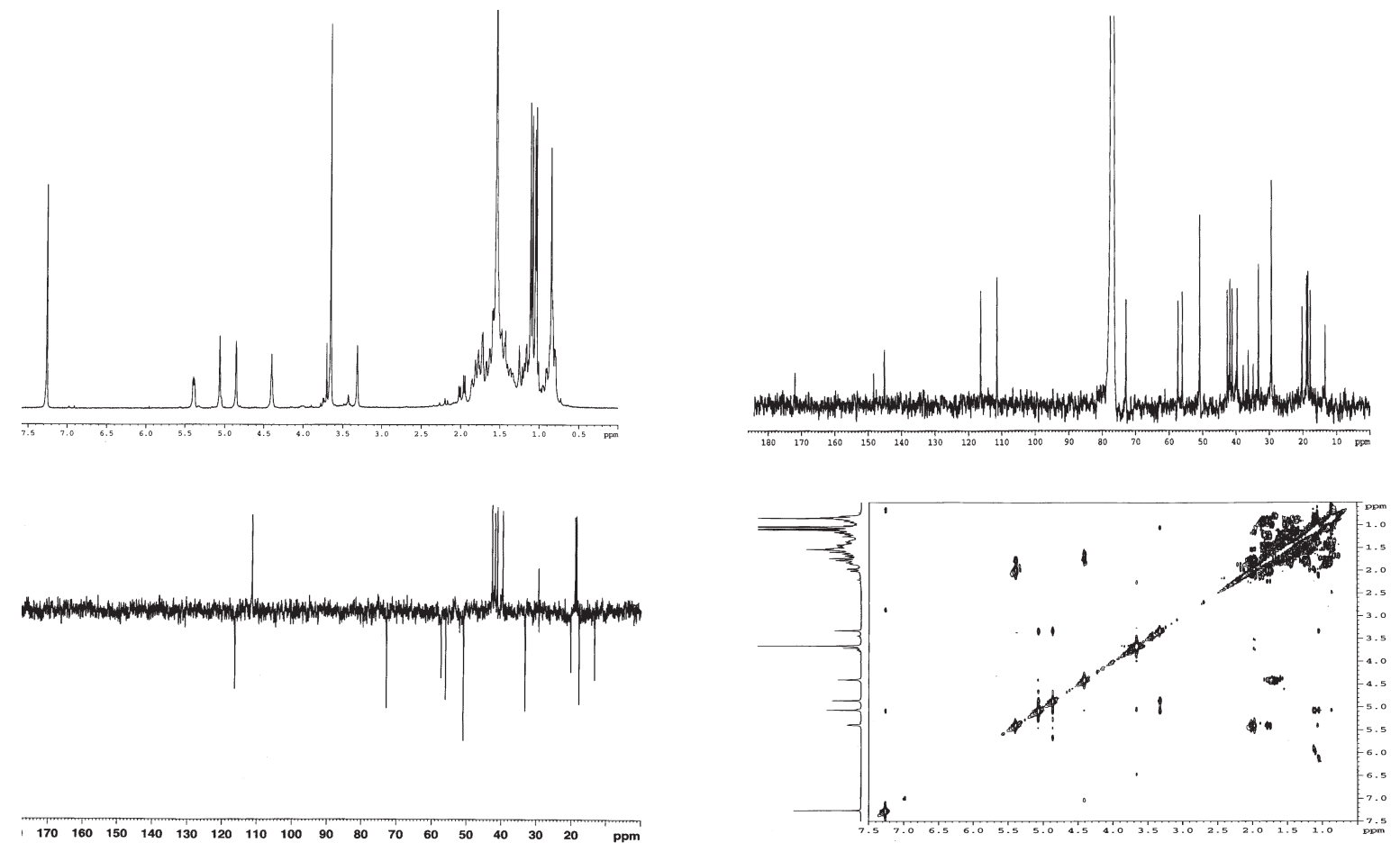

Fig. 7. The 1H, 13C, ${ }^{13} \mathrm{C}$ NMR DEPT, and 2D-NMR ${ }^{1} \mathrm{H}-{ }^{1} \mathrm{H}$ COSY NMR spectra of 21.

Analysis of ${ }^{1} \mathrm{H}$ and ${ }^{13} \mathrm{C}$ NMR spectra of 21 [Fig.7 in[ 44]] in comparison with those of 18 [45,46] showed that the difference was in the presence of a trisubstituted double bond $\left[\delta_{\mathrm{C}} 148.1\right.$ (s) and $\left.116.4(\mathrm{~d}) ; \delta_{\mathrm{H}} 5.39(\mathrm{~m})\right]$ in the scalarane skeleton of 21. The ${ }^{1} \mathrm{H}-{ }^{1} \mathrm{H}$ COSY spectrum indicated that the olefinic proton at $\delta 5.39$ (H-6) was correlated to a methylene $\left(\mathrm{H}_{2}-7\right)$ resonating at $\delta 1.77(\mathrm{~m})$ and $1.99(\mathrm{dd}, J=17.5)$ linked to a quaternary carbon, according to the position of the double by the down-field shifted ${ }^{13} \mathrm{C}$ values of both $\beta$-methyl groups $\mathrm{C}-21(\delta 29.4$ in $21, \delta 21.3$ in 18$)$ and $\mathrm{C}-23(\delta$ 20.3 in $\mathbf{2 1}, \delta 16.2$ in 18) of the scalarane framework, due to the different steric arrangement of ring $\mathrm{B}$ and absence of the $\gamma$-gauche effect of C-6. All proton and carbon resonances, assigned by 2D-NMR $\left({ }^{1} \mathrm{H}-{ }^{1} \mathrm{H}\right.$ COSY, HMQC, and HMBC) experiments as reported in Section 4, were in agreement with the proposed structure 21. Once its structure was proved, ester 21 was subsequently used to functionalize the ring B of the scalaranic framework.

\section{Conclusions}

Physical methods of study are an integral part of modern chemistry and will continue to play a greater role in achieving important scientific results.

Recently, the Centre "Physical Chemistry and Nanocomposites" was created in the frames of the Institute of Chemistry of the ASM.

The main objectives of the Centre are:

- Research in the fields in quantum chemistry, chemical kinetics, nanocomposites, analytical chemistry, hydrogen production and storing, bioinorganics, according to the scientific fields of the laboratories of the centre.

- Modern analyses for (Elemental analysis - C,H.N,S, metals; IR (250-4000 cm-1); UV/Vis (380-780 nm); RMN $\left({ }^{1} \mathrm{H},{ }^{19} \mathrm{~F},{ }^{13} \mathrm{C},{ }^{15} \mathrm{~N},{ }^{31} \mathrm{P},{ }^{119} \mathrm{Sn},{ }^{59} \mathrm{Co}\right.$ etc $)$; RNG $\left({ }^{57} \mathrm{Fe},{ }^{119 \mathrm{~m}} \mathrm{Sn}\right)$; mass-spectrometry; thermal differentiated analysis; atomic absorption analysis; magnetochemistry; electronic microscopy, at the needs of chemistry related institutions, involved in institutional projects, state programs, grants. 
- Special courses regarding physical methods in chemistry for universities students, master students, PhD students and for lecturers and scientists during refresher courses.

- Practical work and production practices on the basis of physical methods in chemistry for young researchers and lecturers during refresher courses.

- Training of highly qualified scientific staff through PD courses and postdoctoral education in the field of physical and physical-chemical research methods.

The centre is endowed with modern equipment. During 2007-2008 the following equipment was purchased: NMR spectrometer $400 \mathrm{MHz}$ (NRM 400), Gamma nuclear resonance Spectrometer (Mössbauer Spectrometer), a system for the determination of materials specific area and pores volume, FTIR Spectrometer, UV/Vis Spectrometer, Elemental analyzer, SF E-100 Stopped Flow Spectrometer, КФК-2 Colorimeter, magnetic stirrers with heating, electronic weights, rotavapors.

\section{Acknowledgements}

I express my sincere thanks for the text on the topics: IR, UV-Vis spectroscopy - $\mathrm{d} / \mathrm{h}$ Fillipov M.P.; Atomic spectroscopy - Mitina T.F.; Mass-spectrometry - PhD Indricean C.; Nuclear Magnetic Resonance (NMR) - PhD Manole S., d/h Makaev, F.; d/ h Ungur, N.

\section{References}

[1]. Filippov, M.P. Thesis of doctor-habilitat of sciences "The nature of chemical bonds in plant tissues; structure and IR spectra as a basis for the classification of pectin compounds.” MAC IC AŞM, 1990. 269 p.

[2]. Vlad, P.F., Khariton H. Sh., Koltsa M. N, Bordeaux O. D, Chemistry of Natural Compounds, 1974, № 1, 24-30.

[3]. Zhungietu, G.I, Rehter, M.A, Izatin and its derivatives, Kishinev, Shtiintsa, 1977.

[4]. Radul, OM, Buhanyuk, SM, Zhungietu, GI, Rehter, MA, Izv. Academy of Sciences of Moldova, Biol. and chem. Science, 1992, № 1, p.47.

[5]. Vaysbeyn, Zh.Yu., Abstract of PhD theses, Kishinev, 1977.

[6]. Indrichan, KM, Abstract of PhD theses, Kiev, 1984.

[7]. Palii, S.P.; Abstract of PhD theses, Odessa, 1991.

[8]. Druță, V.I.; Abstract of PhD theses, Chişinău, 2006.

[9]. Gerbeleu, N.V.; Indrichan, K.M.; J. Inorgan. Chem.(russ), 1981, v. 26, № 2, 291.

[10]. Gerbeleu, N.V.; Indrichan, K.M.; J. Structur. Chem.(russ), 1988, v. 29, № 6, 42.

[11]. Gerbeleu, N.V.; Indrichan, K.M.; Mass-spectrometry of coordination compounds, Kishinev, Shtiintsa, 1984.

[12]. Gerbeleu, N.V.; Indrichan, K.M.; Mass-spectrometry of coordination compounds in the book «The massspectrometric characteristics of organic and elementorganic compounds», Ufa, 1989.

[13]. Gerbeleu, N.V.; Batsanov, A.S.; Timko, G.A.; Struchkov, Yu.T.; Indrichan, K.M.; Popovich,G.A. Dokl. AS USSR, 1987, v. 293, № 2, 364.

[14]. Gerbeleu, N.V.; Batsanov, A.S.; Timko, G.A.; Struchkov, Yu.T.; Indrichan, K.M.; Popovich,G.A. Dokl. AS USSR, 1987, v. 294, № 4, 878.

[15]. Goldansky,V.I., Alekseev,V.P, Stukan,R.A., Turta, C.I. Dokl. AN USSR.1973. T. 213, N4, C.867-871.

[16]. Ponomarev V.I.; Filipenko, O..S.; Atovmyan, L.O.; Bobkova, S.A.; Turte. C.I. Dokl. AN USSR. 1982. T.262, N2, S.346-350.

[17]. Lupu, D.; Barb, D.; Giloti, G.; Morariu, M.; Țărînă. D. J.Inorg.Nucl.Chem. 1972. Vol.34, Nr.9. P.2803-2810.

[18]. Brown, D.B.; Wrobleski, J.T. "Applications of the Mössbauer Effect to the Study of Mixed-Valence Compounds." In the book Mixed-Valence Compounds. Dordrecht, 1979. P.243-270.

[19]. Turta C.I. Theses of doctor habilitat "Dynamic effects in single-and multi-coordination compounds of iron with polydentate ligands (synthesis, structure, the MS-spectra, magnetic properties), Institute of Chemistry, AN MSSR, Kishinev. 1988. 456s.

[20]. Ponomarev, V.I.; Atovmyan, L.O.; Bobkova,S.A.; Turta, C.I. Dokl. AN USSR. 1984. T.274, Nr.2. S.363-373.

[21]. Turta, C.I.; Prodius, D.N.; Mereacre, V.M.; Shova, S.G.; Gdaniec, M.; Simonov, Yu. A.; Kuncser, V.; Filoti, G.; Caneschi, A.; Sorace, L. Inorganic Chemistry Communications. (2004): 7, № 4, 576-579.

[22]. Prodius, D. PhD theses "Sinthesis and study of homo- and heteronuclear iron clusters with di -and triacetic acids", http://www.cnaa.acad.md/thesis/6180/2007, 125 p.

[23]. Turta, C.I. «Investigation of iron complexes with organic ligands by the method of gamma-resonance spectroscopy». Abstract of PhD theses. Science. Kishinev. 1971. 17p.

[24]. Stukan, R.A. «Gamma-resonance spectroscopy to study the structure of complex and organometallic compounds». Abstract of PhD theses. Science. Moscow. 1974. 36s. 
[25]. Shova, S.G. "Synthesis, structure and properties of iron(III) complexes with ligands based onalkilizotiosemikarbazides. PhD theses. Kishinev. 1984. 219s.

[26]. Byrka, M.S. «Synthesis and study of magnetic properties of iron(III) coordination compounds with tetradentate halkogensemikarbazides». Abstract of PhD theses. Science. Kishinev. 1993. 15s.

[27]. Zubarev. V.E. “Iron diocsimates with nitrogen, phosphorus and arsine ligands." $\mathrm{PhD}$ theses. Institute of Chemistry AN MSSR. Kishinev. 1987, 165 pp.

[28]. Bulhac. I.I. "Sinthesis, phisico-cemical prpperties and structure of iron, cobalt and nickel coordination compounds with $\alpha$-dioxime". Theses of doctor habilitat, Institute of Chemistry of ASM, Chişinău, 2000, 232 p +9 annexes.

[29]. Muntyan, S.A. «Sorption of Ni(II), Co(II), Fe(II), Fe(III) and Cr(VI) complex ionite». Abstract of PhD theses. Science. Kishinev. 1982. 16s.

[30]. Gafiychuk, V.A. «Influence of reaction medium on the chemical environment of iron (III) in nitrogen-and oxygenpolymers». Abstract of PhD theses. Science. Kishinev. 1989. 14s.

[31]. Gutsanu, V.L. «Sorption and the state of some metal ions in ionite». Abstract of PhD theses. Science. Kishinev. 1995. 40p.

[32]. Ciobanu, M. "Sorbtion of tensioactive substances and of heavy metals on carbonic adsorbants". Abstract of doctor-habilitat theses in chemistry, USM, Chisinau, 2006, 37p.

[33]. Bobkova, S. A. «The synthesis and study of trinuclear mixed valence iron (II, III, III) carboxylates», PhD theses, Kishinev, 1982., 132c.

[34]. Lazarescu, A. "Oxotrinuclear complex compounds of iron with amino acids", Abstract of PhD theses, The Institute of Chemistry of ASM, Chişinău-Universitatea Bucureşti, 1997, 133p.

[35]. Mereacre, V. "Oxotrinuclear complex compounds of iron with fat acids", PhD theses, The Institute of Chemistry of ASM, Chişinău, 2000, 131p.

[36]. Stratulat, Iu.I. "Evoluția proprietăţilor fundamentale ale hemoglobinei la etapele timpurii de dezvoltare a reacției metabolice a organismului (sub acțiunea factorului extremal mecanic)". Abstract of PhD thesis in biology, USM, Chişinău 1996, 21p.

[37]. Alekseev, V.P. «The study of delocalization and fast electronic process by method of gamma-resonance spectroscopy». Abstract of PhD thesis in physics and mathematics. AN USSR. ICP. Moscow 1974. 19s.

[38]. Horoshun, I..V. "Polynuclear heterometal coordination compounds of some $3 \mathrm{~d}$ elements with $\alpha$-dioximes". Abstract of $\mathrm{PhD}$ thesis. Kishinev 1983, 16p.

[39]. Маноле, С.Ф.; Барба, Н.А.; Кептенару, К.Ф. «Атлас спектров азотсодержащих виниларенов». Кишинев, Штиинца, 1987, 328c.;

[40]. Маноле, С.Ф.; Барба,Н.А.; Кептенару, К.Ф. «Атлас спектров азот- и серосодержащих виниларенов». Кишинев, Штиинца, 1988, 232c.

[41]. Барба, Н.А.; Доня, А.П.; Шур, А.М. «Азотсодержащие винилирены». Кишинев, изд. Штиинца, 1985, $166 \mathrm{c}$.

[42]. Jansen, B. J. M.; Hendrikx,C.C.; Masalov, J. N.; Stork, G.A.; Meulemans, T.M.; Macaev, F.Z.; de Groot, A. Tetrahedron 2000, 56, 2075-2094.

[43]. Meulemans, T.M.; Stork, G.A.; Macaev, F.Z.; Jansen, B.J. M.; de Groot, A. J. Org. Chem. 1999, 64, 9178-9188.

[44]. Kulcitki, V.; Ungur, N.; Gavagnin, M.; Castelluccio, F.; Cimino, G. Tetrahedron, 2007, 63, 7617-7623.

[45]. Ungur, N.; Gavagnin, M.; Cimino, G. Nat. Prod. Lett. 1996, 8, 275.

[46]. ${ }^{13} \mathrm{C}$ NMR values of the pairs C-9/C-18 and C-24/C-25 of ester 18 reported in Ref. 45 should be inverted and

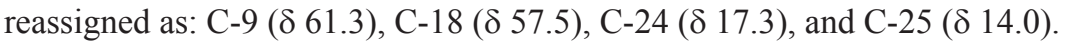

